\title{
Share your geoscience resources in EarthCube's Paleogeoscience Catalog
}

David Anderson, K. Horlick and R. Lingo

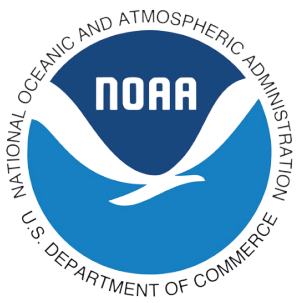

\section{Your input is needed to produce a new, comprehensive, and openly accessible catalog of paleogeoscience resources, including databases, sample repositories, and shared software.}

Imagine a world where the global community of Earth scientists are well-connected, where resources such as data, software, sample repositories, journal articles, and social networking combine efficiently to accelerate the pace of discovery, where the infrastructure enables new approaches, where the time needed to manage data is reduced enabling more time to do science. This is the world envisioned by EarthCube, a US National Science Foundation sponsored long-term effort to develop cyberinfrastructure, bridge disciplines, and unlock the power of sharing tools, data, and information.

EarthCube was launched in 2011. Over 2500 scientists have contributed to the current structure and program development (Richard et al. 2014). EarthCube hopes the planned changes to Earth Science will be comparable in speed and breadth to the spread of the Internet or other basic Infrastructures. The EarthCube system will enable data intensive science, become an integral part of everyday research, and provide access to people, tools, and data.

The data management component will improve the availability and documentation of scientific data, enabling synthesis and re-use. Resource catalogs will put lists of software, data, and sample repositories on your desktop. Data and software will be integrated to simplify access, analysis, and visualization. Results will be piped between processes in reproducible workflows. Stovepipes constraining narrow disciplines will be removed enabling data and tools originating in one discipline to be applied in another.

One of the first steps to create this new world is to develop a catalog of resources. So the World Data Center for Paleoclimatology is now reaching out to PAGES scientists and educators, to help you add information about databases, software, and repositories to a central and comprehensive catalog of paleogeoscience resources.

\section{Project history}

The National Oceanic and Atmospheric Administration (NOAA) is spearheading the catalog development for the EarthCube project titled "C4P: Research Coordination Network for Paleogeosciences". The C4P

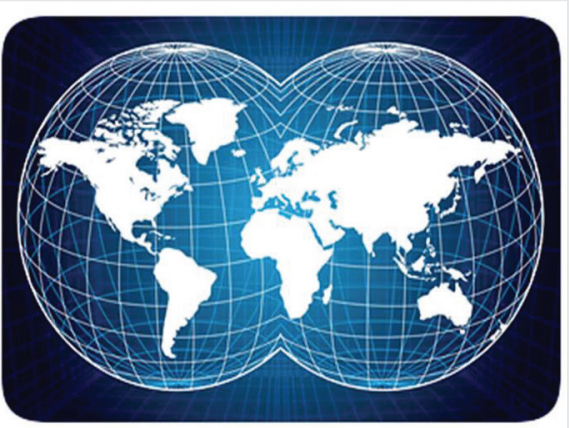

PACSES PAST GLOBAL CHANGES EARTHCube

project connects with an Earth-Science-wide cataloging effort titled CINERGI that has the goal to build a comprehensive system linking geoscience resources, users, publications, usage information, and cyberinfrastructure components. The initial CINERGI catalog, with some paleoclimate entries, can be found at http://hydro10.sdsc.edu. A pivot table view exists at http://hydro10.sdsc edu/c4pviewer/CommunityPivot.html. Both C4P and CINERGI produce resources that can be shared worldwide beyond the Earth Science discipline, for example through resource sharing platforms such as SciCrunch (scicrunch.com). In the future, informatics experts hope to create a catalog of resources that embraces all scientific disciplines.

\section{The catalog idea}

The guiding idea of the cataloguing effort is to help scientists discover samples, software, and data and use these resources in new and creative ways. Some PAGES-relevant resources are well known, for example the IMAGES and IODP marine sediment core collections, the PANGAEA and NOAA databases, and various radiocarbon calibration software packages. However, many resources that could be shared to the benefit of providers and users are instead hidden or hardly traceable. Cores and sample collections sometimes remain in the laboratories of individual investigators long after projects have been completed. Software that could be shared is used only by one team of inves tigators. Sharing resources accomplishes several goals that accelerate the pace of science and advance discovery. One goal is to identify best practices and unusually significant samples and data sets. Pilot studies made on already-existing samples can provide crucial evidence needed to secure research funding. Another goal is to enable resources used in one field, or for one scientific question, to be applied to other problems. For example, mosquitos collected and preserved by entomologists years ago, their skeletons affixed with pins to a board, have been sampled by epidemiologists to understand the spread of the West Nile virus using the DNA found in the mosquito's bodies (Kaufmann et al. 2003).

\section{Feed the catalog}

We need your input and suggestions to produce the catalog of paleogeoscience resources. Input from scientists in the PAGES community is vital to make the catalog a comprehensive and truly international resource. We want your suggestions of software and databases focused on or relevant to paleogeosciences.

\section{- Software should be non-commercial, and should be paleogeoscience-specific, such as radiocarbon calibration code or CoreWall (corewall.org).}

- Databases for the catalog are defined as having an online searchable interface.

Paleogeosciences encompasses both paleoenvironmental and paleobiological research, including paleoclimatology, paleoecology, paleogeography, geochronology, and geochemistry. Conceptually these topics focus on past Earth and life processes.

To contribute a resource, email paleo@noaa. gov with the name of the software or database resource, the URL, and a two-sentence description, with "EarthCube" in the subject line.

\section{AFFILIATIONS}

World Data Center for Paleoclimatology, NOAA's National Climatic Data Center, Boulder, USA

\section{CONTACT}

Kaleb Horlick: kaleb.horlick@noaa.gov

\section{REFERENCES}

Kaufmann EB et al. (2003) J Clin Microbiol 41: 3661-3667

Richard SM et al. (2014) Eos 95(20): 165-176 